\title{
Effect of drip-irrigation with saline water on Chinese rose (Rosa chinensis) during reclamation of very heavy coastal saline soil in a field trial
}

\author{
Xiaobin Li ${ }^{a, b}$, Yaohu Kang ${ }^{\mathrm{a}, *}$, Shuqin Wan ${ }^{\mathrm{a}}$, Xiulong Chen ${ }^{\mathrm{a}, \mathrm{b}}$, Jiachong Xu ${ }^{\mathrm{a}, \mathrm{b}}$ \\ a Key Laboratory of Water Cycle and Related Land Surface Processes, Institute of Geographic Science and Natural Resources Research, \\ Chinese Academy of Sciences, Beijing 100101, China \\ ${ }^{\mathrm{b}}$ University of Chinese Academy of Sciences, Beijing 100049, China
}

\section{A R T I C L E I N F O}

\section{Article history:}

Received 23 December 2014

Received in revised form 15 February 2015

Accepted 18 February 2015

Available online 6 March 2015

\section{Keywords:}

Sandy loam

Salt leaching

Plant growth

Dry mass

Threshold

\begin{abstract}
A B S T R A C T
Drip-irrigation with saline water was used for reclamation of very heavy coastal saline soils and its effects on salt-sensitive plants were also evaluated in a three-year trial in the coastal region of east China. The original soil salinity expressed as electrical conductivity of the saturation paste extract $\left(\mathrm{EC}_{\mathrm{e}}\right)$ was an average of $27.13 \mathrm{dS} / \mathrm{m}$ in the $0-100 \mathrm{~cm}$ depth. The experiment included five treatments of salinity levels of $0.8,3.1,4.7,6.3$ and $7.8 \mathrm{dS} / \mathrm{m}$ of irrigation water. Chinese rose (Rosa chinensis), a salt-sensitive species, were planted in the sandy loam soil to determine the effect of saline environment on growth characters and dry matter production. Drip-irrigation had a significant positive impact on salt leaching, and the very highly saline soil became mildly saline after reclamation in root zone of soil profiles irrigated with water of salinity up to $7.8 \mathrm{dS} / \mathrm{m}$. An increase in salinity of irrigation water had adverse effects on plant height, stem diameter, survival rate and dry matter production. Root:shoot ratio increased with increasing water salinity. The values of soil-salt tolerance threshold were $2.39 \mathrm{dS} / \mathrm{m}$ at emergence and $2.78 \mathrm{dS} / \mathrm{m}$ in the growth period after emergence. The emergence rate and dry mass decreased by 27.39 and $41.19 \%$ for each unit of $\mathrm{EC}_{\mathrm{e}}$ increase in the root zone, respectively. These results implied that drip-irrigation with saline water by controlling soil matric potential under a gravel-sand layer was effective in reclamation of this very heavy coastal saline soil for sensitive species such as Chinese rose.
\end{abstract}

(C) 2015 Elsevier B.V. All rights reserved.

\section{Introduction}

There is an increasing demand for land resources in coastal areas with the rapid social and economic development, and sea reclamation has become an effective way for extension of land resources in these regions. However, most of these soils cannot be initially used for landscape plants due to their high levels of salt. For example, the mean electrical conductivity of saturated paste extracts $\left(\mathrm{EC}_{\mathrm{e}}\right.$ ) is up to $66.7 \mathrm{dS} / \mathrm{m}$ in Tianjin coastal soils (Sun et al., 2013) and $28 \mathrm{dS} / \mathrm{m}$ in our study area in China - with the salt composition mainly chlorides, in which chloride and sodium $\left(\mathrm{Na}^{+}\right)$account for $60-88 \%$ of the anion and cation concentrations, respectively. Accumulation of excess $\mathrm{Na}^{+}$in soil causes numerous

\footnotetext{
* Corresponding author at: Key Laboratory of Water Cycle and Related Land Surface Processes, Institute of Geographic Science and Natural Resources Research, Chinese Academy of Sciences, 11A Datun Road, Anwai, Beijing 100101, China. Tel.: +8610 64856516; fax: +861064856516.

E-mail address: kangyh@igsnrr.ac.cn (Y. Kang).
}

adverse phenomena, such as changes in exchangeable and soil solution ions and soil $\mathrm{pH}$, destabilization of soil structure, deterioration of soil hydraulic properties, increased susceptibility to crusting and imbalances of plant-available nutrients in the soils (Akhter et al., 2004; Khoshgoftarmanesh et al., 2003; Prichard et al., 1985; Qadir et al., 2005). Saline-sodic soils can slake, disperse and swell under specific conditions when wet with rain or irrigation water; this decreases water and air movement, plant-available water, root penetration, seedling growth and plant establishment; increases runoff, ponding, water-logging and erosion; and impedes seed bed preparation (Akhter et al., 2004; Oster et al., 1999; Sumner, 1993). The harsh soil environment has caused poor landscapes in these regions, with reed [Phragmites australis (Cav.) Trin. Ex Steud.] and suaeda (Suaeda glauca Bge.) the only native vegetation found. There is an urgent need to improve the landscape to meet the demand of living environments for cities and districts (Li et al., 2015).

Many methods including engineering, mechanical, chemical and biological have been used for reclamation of the coastal saline wasteland in attempts to improve the landscape, but were found ineffective due to high cost or water limitation. Using such methods, 
it is difficult to create a good landscape in a short time and to maintain good plant growth. It is thus necessary to develop a method to reclaim the very heavy coastal saline soils for construction of ecological landscapes in these regions.

Unsaturated soil moisture flow has been shown to be more water-saving and effective in leaching salt than saturated moisture flow (Selassie et al., 1992). Drip-irrigation is an effective irrigation technique for applying unsaturated soil moisture flow with the design of suitable dripper flow according to soil texture and improved water use efficiency. It has been found highly applicable for utilization and reclamation of saline soils (Kang et al., 2010; Liu et al., 2012; Sun et al., 2013; Wan et al., 2012; Wang et al., 2012). However, irrigation of increasing amounts of landscape will consume a large quantity of water, and fresh water resources are very limited in coastal regions. Some non-conventional water resources such as saline water, brackish groundwater and treated wastewater should be sought as alternatives to fresh water (Rhoades et al., 1988). Saline water is an ideal alternative in coastal regions, where saline water resources are plentiful, and have been successfully used for irrigating crops and other plants. Drip-irrigation is also widely regarded as the most promising irrigation system for use with saline water (Malash et al., 2008; Meiri et al., 1992). It applies water precisely and uniformly at high frequencies, maintains high soil matric potential (SMP) in the root zone and thus compensates for the decreased osmotic potential caused by irrigation with saline water, and a constant high total water potential can be maintained for crop and plant growth (Goldberg et al., 1976; Kang, 1998). The questions that arise are how much water should be used for leaching and when leaching should be applied.

Roses are some of the most popular flowering plants in the world, and their widespread cultivation and versatility have led to diversity in color and forms of flowers, plant habit and environmental adaptability (Cai et al., 2014). Roses are also one of the most common and basic of landscaping plants; however, they are generally sensitive to salinity of $>3.0 \mathrm{dS} / \mathrm{m}$ EC. Grown rose crop of the threshold value was reported as $1-2.4 \mathrm{dS} / \mathrm{m}$ in soilless cultures and $1-3 \mathrm{dS} / \mathrm{m}$ in soil cultures which were calculated by flower characteristics (De Kreij and Berg, 1990; Feigin et al., 1989; Hughes and Hanan, 1978; Ishida et al., 1979; Sonneveld et al., 1999; Yaron et al., 1969; Zeroni and Gale, 1989). Chinese rose (Rosa chinensis), a conventional landscape flower plant and sensitive to soil salinity, was examined in the present study. The aim was to determine a suitable management method for reclamation of very heavy coastal saline soils using drip-irrigation with saline water on salt-sensitive plants for landscape improvement. Specifically, the objective was to test the impact of irrigation with saline water on plant growth and dry matter production during reclamation of the saline soil. We envision that our approach will be useful in relieving the water supply pressure on ecological economics and improving the landscape environment in coastal regions.

\section{Materials and methods}

\subsection{Experimental site}

The experiment was carried out during 2012-2014 at the Industrial Areas of Caofeidian District $\left(39^{\circ} 03^{\prime} \mathrm{N}, 118^{\circ} 48^{\prime} \mathrm{E}\right)$ in the south of Tangshan city, east China, and north of Bohai Gulf which borders the Pacific Ocean. The station has a typical semi-humid monsoon climate with annual precipitation of approximately $580 \mathrm{~mm}$, mostly during June-September (Fig. 1). The land of the site was formed by sea reclamation. The $\mathrm{EC}_{\mathrm{e}}$ and sodium adsorption rate (SAR) of the soil at a depth of $100 \mathrm{~cm}$ were $27.13 \mathrm{dS} / \mathrm{m}$ and $51.88(\mathrm{mmol} / \mathrm{L})^{0.5}$, respectively. The soil bulk density of the initial saline soil was in the range of $1.6-1.75 \mathrm{~g} / \mathrm{cm}^{3}$. According to the USDA soil classification, the soil in our experiment field was sandy loam soil.
The soil texture, soil bulk density, $\mathrm{EC}_{\mathrm{e}}, \mathrm{pH}$ and SAR are shown in Table 1.

\subsection{Experimental design}

\subsubsection{Plot layout and irrigation water management}

The soil treatment was as described in Li et al. (2015). Soil was removed to a depth of $100 \mathrm{~cm}$ and a $15-\mathrm{cm}$ thick gravel layer was laid in the bottom and then covered with a $5-\mathrm{cm}$ thick layer of sand with native soil placed back above the sand. A rotary tiller was used to break clay blocks and oyster shell of the soil surface to increase soil infiltration. Five treatments with $\mathrm{EC}$ of irrigation water $\left(\mathrm{EC}_{\mathrm{iw}}\right)$ of 0.8 (K1), 3.1 (K2), 4.7 (K3), 6.3 (K4) and 7.8 (K5) dS/m were designed, with saline water composed by mixing fresh well-water and highly saline shallow-groundwater in different proportions. Ionic composition of irrigation water is shown in Table 2. Each treatment had three replications and the 15 plots were laid out permanently following a completely randomized block design. There were 56 roses planted at a spacing of $0.5 \mathrm{~m} \times 0.6 \mathrm{~m}$ in each $4.0 \mathrm{~m} \times 4.0 \mathrm{~m}$ experimental plot.

Each treatment had a separate gravity drip-irrigation system consisting of a 200-L tank and 21 drip tubes (seven tubes per plot). The tank was installed $0.8 \mathrm{~m}$ above the ground to contain irrigation water. Drip tubes with $0.2-\mathrm{m}$ emitter intervals were placed in position at $0.05 \mathrm{~m}$ from roses. One vacuum gauge tensiometer (WST-1, China) was installed $0.2 \mathrm{~m}$ directly underneath the emitter located in the center of the plot for each treatment. The tensiometer was observed twice daily (at 8:00 and 18:00 h), and irrigation was applied when the tensiometer reading exceeded the target SMP value.

The primary irrigation strategies are controlling the SMP at a depth of $20 \mathrm{~cm}$ immediately under the emitter throughout the growing season. The optimal SMP threshold was $-5 \mathrm{kPa}$ for the first year, and SMP threshold could be controlled at slightly higher than $-5 \mathrm{kPa}$ according to the soil salinity environment from the second year. Based on the experimental results of Sun et al. (2012, 2013), we set the SMP threshold at $-5 \mathrm{kPa}$ when the roses were transplanted; $-10 \mathrm{kPa}$ after a growing season ended; $-15 \mathrm{kPa}$ after October 2013, taking into account the rapid salt leaching; and returned to $-10 \mathrm{kPa}$ in 2014 .

Irrigation time was divided into two stages. The first stage was enhanced salt leaching. Its purpose was to rapidly leach salt from 0 to $10 \mathrm{~cm}$ of the soil profile to create a low-salt area for plants, which could prevent salt from the soil surface moving into the planting hole with runoff or soil water movement. This stage used the same gravity drip-irrigation system. The water head was located $0.5 \mathrm{~m}$ above the soil surface and was controlled by a bucket in which a float had been installed. The emitter discharge rate was $0.4 \mathrm{~L} / \mathrm{h}$ under the water head. Two drip tubes were placed at $30 \mathrm{~cm}$ distance between two closed rows of rose transplants and the distance between emitters was $20 \mathrm{~cm}$. During the first $3 \mathrm{~d}$ after rose transplanting if water ponding and runoff appeared on the soil surface during irrigation, then the irrigation was stopped and only started again when the water on the soil surface disappeared. If rainfall occurred, the irrigation time was increased in order to prevent the salt at the perimeter of the surface wetted soil moving back toward the plant in any water flow from the perimeter to the emitter or the rose root-zone.

The second stage was normal water-salt regulation. Irrigation started based on SMP. Immediately after transplanting the rose seedlings on 6 June 2012, $78 \mathrm{~mm}$ of freshwater was applied over a period of $3 \mathrm{~d}$ to reduce the soil salinity within the $0-10 \mathrm{~cm}$ soil layer. After the initial $3 \mathrm{~d}$, the transplants were still establishing, so if SMP fell below $-5 \mathrm{kPa}$, all treatments were uniformly irrigated to maintain SMP at $-5 \mathrm{kPa}$, until all rose plants had successfully established in the experimental soil. The enhanced salt leaching 

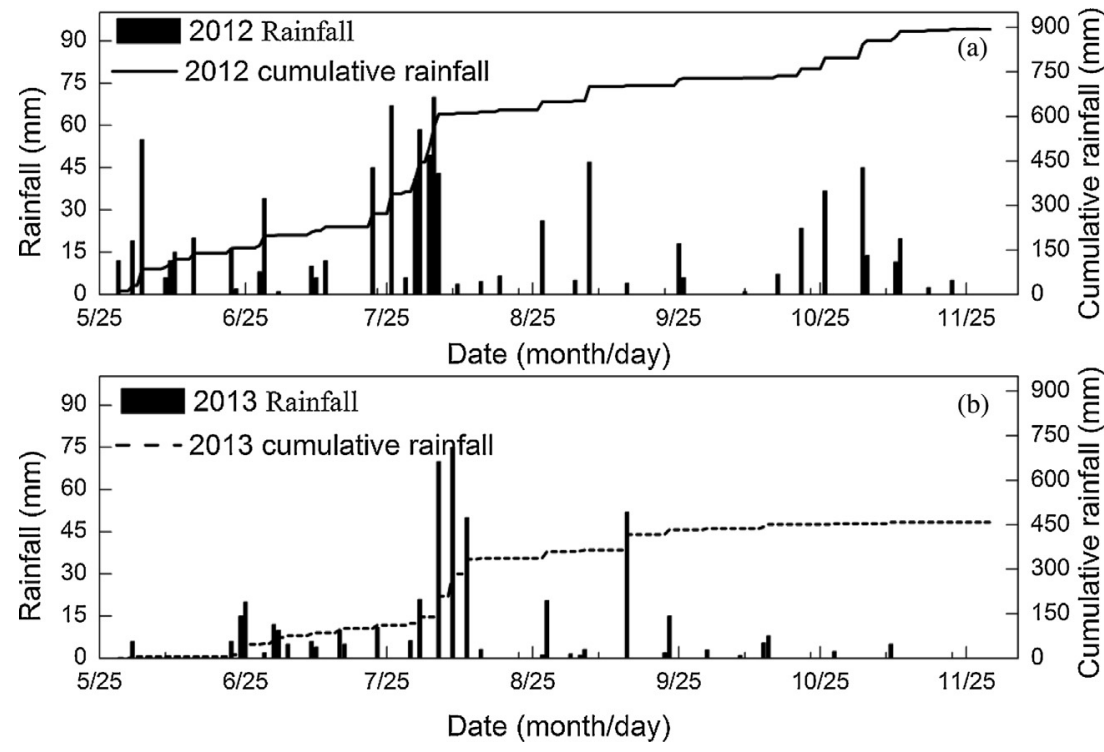

Fig. 1. The daily and cumulative rainfall during the growing seasons of Chinese rose in 2012 and 2013.

Table 1

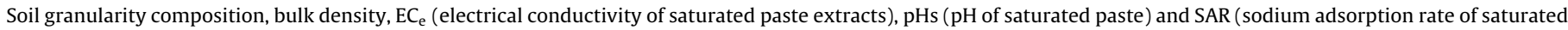
paste extracts) in initial sandy loam soil.

\begin{tabular}{|c|c|c|c|c|c|c|c|}
\hline \multirow[t]{2}{*}{ Soil depth $(\mathrm{cm})$} & \multicolumn{3}{|c|}{ Soil granularity composition (\%) } & \multirow[t]{2}{*}{ Bulk density $\left(\mathrm{g} / \mathrm{cm}^{3}\right)$} & \multirow[t]{2}{*}{$\mathrm{ECe}(\mathrm{dS} / \mathrm{m})$} & \multirow[t]{2}{*}{$\mathrm{pHs}$} & \multirow[t]{2}{*}{$\mathrm{SAR}(\mathrm{mmol} / \mathrm{L})^{0.5}$} \\
\hline & $<0.002 \mathrm{~mm}$ & $0.002-0.05 \mathrm{~mm}$ & $0.05-2 \mathrm{~mm}$ & & & & \\
\hline $0-10$ & 0.25 & 40.90 & 58.85 & 1.30 & 28.85 & 7.83 & 54.28 \\
\hline $10-20$ & 0.51 & 42.67 & 56.82 & 1.43 & 28.73 & 7.83 & 55.53 \\
\hline $20-30$ & 0.42 & 44.70 & 54.89 & 1.55 & 28.11 & 7.86 & 55.14 \\
\hline $30-40$ & 0.45 & 47.44 & 52.11 & 1.69 & 27.62 & 7.97 & 53.53 \\
\hline $40-60$ & 0.36 & 42.46 & 57.18 & 1.65 & 25.41 & 8.09 & 52.43 \\
\hline $60-80$ & 0.49 & 41.39 & 58.12 & 1.70 & 26.75 & 7.99 & 47.89 \\
\hline $80-100$ & 0.60 & 45.10 & 54.31 & 1.66 & 26.84 & 7.98 & 49.85 \\
\hline
\end{tabular}

Table 2

Ionic composition of irrigation water.

\begin{tabular}{|c|c|c|c|c|c|c|c|}
\hline \multirow[t]{2}{*}{$\mathrm{EC}_{\mathrm{iw}}(\mathrm{dS} / \mathrm{m})$} & \multicolumn{5}{|c|}{ Ionic concentration $(\mathrm{mmol} / \mathrm{L})$} & \multirow[t]{2}{*}{$\mathrm{pH}$} & \multirow[t]{2}{*}{$\mathrm{SAR}(\mathrm{mmol} / \mathrm{L})^{0.5}$} \\
\hline & $\mathrm{Na}^{+}$ & $\mathrm{K}^{+}$ & $\mathrm{Ca}^{2+}$ & $\mathrm{Mg}^{2+}$ & $\mathrm{SO}_{4}{ }^{2-}$ & & \\
\hline 0.8 & 11.88 & 0.35 & 1.35 & 0.41 & 0.17 & 8.92 & 8.95 \\
\hline 3.1 & 25.07 & 0.52 & 2.50 & 2.10 & 2.51 & 8.67 & 11.69 \\
\hline 4.7 & 35.72 & 0.74 & 3.72 & 3.39 & 4.22 & 8.66 & 13.39 \\
\hline 6.3 & 48.61 & 1.04 & 3.89 & 5.39 & 6.21 & 8.59 & 15.96 \\
\hline 7.8 & 59.79 & 1.25 & 5.46 & 6.68 & 8.13 & 8.50 & 17.16 \\
\hline
\end{tabular}

$\mathrm{EC}_{\mathrm{iw}}$ : irrigation water electrical conductivity; SAR: sodium adsorption ratio.

stage finished when plants had successfully established, and about $\sim 60 \mathrm{~mm}$ of freshwater was applied over a period of $25 \mathrm{~d}$ to provide favorable soil moisture for their survival.

Water treatments based on different $\mathrm{EC}_{\mathrm{iw}}$ were initiated on 4 July 2012, and the amount of water for each irrigation event of all treatments was $6 \mathrm{~mm}$ when SMP reached the threshold value, which considered the maximum daily evapotranspiration of plants in the local area. The drip tubes were reduced to one per plant row.

During 16-19 November 2012 and 27-30 November 2013, $24 \mathrm{~mm}$ of freshwater irrigation was applied to each treatment and then irrigation was terminated until April due to the onset of winter. During 1-4 April 2013 and 7-10 April 2014, 24 mm of freshwater irrigation was applied to each treatment to provide a suitable soil moisture environment for plant sprouting in spring.

\subsubsection{Fertilization and field management}

The five treatments had the same amount of fertilizer. Phosphoric acid, urea and potassium dihydrogen phosphate were added into the fertilizer tank and dissolved in water so that the fertilizer was applied with the irrigation water, in annual amounts of 60, 73 and $59 \mathrm{~kg} / \mathrm{ha}$, respectively.

Chinese roses were pruned in early December of each year, and were cut to uniform height for the five treatments. In winter of 2012, the plot was fenced with bamboo sticks, and covered with a protective cloth, due to the poor tolerance to cold of these plants in the first year. Other field management included weeding and pest control as used for conventional management of the landscape.

\subsubsection{Observation and measurements}

The number of surviving plants was counted monthly to calculate the survival rate of Chinese rose during 2012-2014, and the emergence rate was counted during March-April every year. The height and stem diameter were measured in 2012 and 2013. The total biomass (fresh and dry weights of shoots and roots) of plants (one plant per replicate) was measured at the end of 2013. 
Soil cores were obtained from each plot using an auger $(2.0 \mathrm{~cm}$ diameter, $15 \mathrm{~cm}$ high; China) on 5 June, 4 July and 28 October 2012; on 12 March and 12 November 2013; and on 24 March 2014. The samples were obtained at $0,10,20$ and $30 \mathrm{~cm}$ from the emitters, respectively, and all sample depths were the same: $0-10,10-20$, $20-30,30-40,40-60,60-80$ and $80-100 \mathrm{~cm}$. The three replicate soil samples were mixed into one sample per treatment.

All soil samples were air-dried and passed through a $1-\mathrm{mm}$ sieve. Soluble salt estimates, soluble cations and soil $\mathrm{pH}$ were based on extracts of saturated soil. The EC and $\mathrm{pH}$ were determined using a conductivity meter (DDS-11A, REX, Shanghai) and a pH meter (PHS3C, REX), respectively. Soluble cations including $\mathrm{Ca}^{2+}, \mathrm{Mg}^{2+}, \mathrm{Na}^{+}$, $\mathrm{K}^{+}$and $\mathrm{SO}_{4}{ }^{2-}$ were measured with ICP-OES (Optima 5300DV, USA). The SAR of the saturated paste extract was calculated as follows (Rhoades et al., 1992):

$\mathrm{SAR}=\frac{\left[\mathrm{Na}^{+}\right]}{\left(\left[\mathrm{Ca}^{2+}\right]+\left[\mathrm{Mg}^{2+}\right]\right)^{0.5}}$

where the concentration of each cation is in $\mathrm{mmol} / \mathrm{L}$.

The average $\mathrm{EC}_{\mathrm{e}}$ values within the whole soil profile or the root zone (identified as in soil about $40 \mathrm{~cm}$ horizontal to the center of two rows at a depth of $0-40 \mathrm{~cm}$ ) were integrated to account for both spatial and temporal variations. The average values of $\mathrm{EC}_{\mathrm{e}}$ in the soil profile were calculated as follows (Dou et al., 2011):

$\mathrm{EC}_{\mathrm{e}}(t)=\frac{\sum_{j, k}^{n, m} \mathrm{EC}_{\mathrm{e}}(t, j, k) \times S(j, k)}{\sum_{j, k}^{n, m} S(j, k)}$

where $t$ represents the time at which soil samples were obtained; $j$ is the four $(n)$ distances from the emitter where soil samples were attained; $k$ is the seven (m) depths of soil samples and $S(j, k)$ the depth interval of the soil sample.

\subsection{Statistical analyses}

Two empirical functions were compared to describe plant growth and dry matter production of roses while subject to increasing levels of root-zone salinity and saline water.

Model 1 is as follows (Mass and Hoffman, 1977):

$\operatorname{PIr}=100-\operatorname{PId}\left(E_{e}-E_{t}\right)$

where PIr is the relative plant index (actual plant index at the given salinity level divided by plant index with fresh water or low saline water), $\mathrm{EC}_{\mathrm{e}}$ represents the average root-zone salinity (EC of the saturated paste extract, $\mathrm{dS} / \mathrm{m}$ ), $\mathrm{EC}_{\mathrm{t}}$ is the threshold salinity level (the maximum allowable salinity that does not reduce plant index measurably below that of a non-saline condition or irrigated with fresh water or low saline water, $\mathrm{dS} / \mathrm{m}$ ), and PId is the plant index decrease per unit of salinity increase beyond the threshold.

Model 2 is as follows (Steppuhn et al., 2005):

$\operatorname{PIr}=\frac{1}{1+\left(C / C_{50}\right)^{\exp \left(s C_{50}\right)}}$

where $C$ is the EC value of the water in $\mathrm{dS} / \mathrm{m}, C_{50}$ defines $C$ at $P I=0.5$ and $s$ represents the response curve steepness.

Salinity tolerance index (STI) is a comprehensive parameter that can reflect and evaluate the plant tolerance to salinity, and can be used for comparison of levels of salt tolerance in different plants (Steppuhn et al., 2005). The STI equals the salinity value $\left(C_{50}\right)$ corresponding to the $50 \%$ reduction in plant index (such as survival rate or dry mass production) from that of non-saline index plus a measure of the tendency to maintain some product index less than but approaching $C_{50}$ when the plant is subjected to salinity levels. STI is calculated as follows (Steppuhn et al., 2005):

$\mathrm{STI}=C_{50}+s C_{50}$
All data gathered in the study were recorded and classified using Microsoft Office Excel 2007. Analyses of variance (ANOVAs) were carried out by SPSS 16.0 statistical software (SPSS Inc., IL, USA). The significance of the effect of all variables was examined by one-way ANOVA. Spatial distributions of salinity indices in a surface made by distance from the emitters $(30 \mathrm{~cm})$ and depth of $100 \mathrm{~cm}$ were created using Surfer 8.0 (Golden Software Inc., CO, USA) and Origin 8.0 (Origin Lab Inc., MA, USA). In order to determine the effect of saline water and soil salt on Chinese rose, as well as evaluate the salt tolerance of plants, the relationship equations between the survival rate, growth and dry mass parameter and the salinity level of water and soil were fitted.

\section{Results and discussion}

\subsection{Rainfall, SMP and irrigation}

The total rainfall was 883.2 and $488.9 \mathrm{~mm}$ in 2012 and 2013 during the experiment period, respectively (Fig. 1). There were five months in 2012 in which monthly rainfall exceeded $80 \mathrm{~mm}$, but only one month in 2013. There was a total of 26 and $14 \mathrm{~d}$ with daily rainfall exceeded $10 \mathrm{~mm}$ in 2012 and 2013, respectively. Overall, precipitation in 2012 was greater than the average rainfall in the area, while that in 2013 was relatively low.

Variations of SMP over time during the growing seasons in 2012-2013 are shown in Fig. 2. In most cases, SMP was basically affected by the SMP threshold values used to trigger irrigation, and the SMP at $0.2 \mathrm{~m}$ depth directly underneath the drip emitter for treatments of different salinities of irrigation water was controlled well above $-5 \mathrm{kPa}$ in 2012 , and -10 and $-15 \mathrm{kPa}$ before and after 1 October 2013, respectively.

More saline water was applied in 2013 than 2012; however, with lower irrigation frequency (data not shown). Irrigation occurred every 3.6-4.10 d in 2012, but every 4.58-5.95 d in 2013 because SMP threshold was controlled lower in 2013 than in 2012. The amount of irrigation with saline water was 190-230 and 220-290 mm in 2012 and 2013, respectively, and irrigation amount declined with increasingly saline water.

\subsection{Salt leaching}

For the experimental site before transplanting of roses, the average $\mathrm{EC}_{\mathrm{e}}$ values in the $0-40$ and $0-100 \mathrm{~cm}$ soil profiles were up to 28.33 and $27.13 \mathrm{dS} / \mathrm{m}$, respectively (Table 1 and Fig. 3). The $\mathrm{EC}_{\mathrm{e}}$ distribution during the reclamation by drip-irrigation with saline water showed a significant decrease in soil salinity for all treatments, and salt leaching decreased with depth (Fig. 3).

The distribution of $E C_{e}$ in $0-40$ and $0-100 \mathrm{~cm}$ soil profiles at the different soil picking seasons for five treatments are shown in Fig. 4. After enhanced salt leaching stage and period of irrigation for rose survival, good and significant salt leaching effect exited in both $0-40$ and $0-100 \mathrm{~cm}$ soil profiles. The average $\mathrm{EC}_{\mathrm{e}}$ values of five treatments in $0-40$ and $0-100 \mathrm{~cm}$ soil profile were 8.67 and $14.46 \mathrm{dS} / \mathrm{m}$ (2012.6-2012.7), respectively, which were reduced by 69.41 and $46.69 \%$ compared to corresponding initial $\mathrm{EC}_{\mathrm{e}}$ values prior to planting, and no obvious trend among treatments was observed. Within the first four months at normal water-salt regulation stage until October 2012, there was still a great reduction in soil salinity and this reduction decreased with increasing salinity of irrigation water. The average $\mathrm{EC}_{\mathrm{e}}$ value of five treatments in 0-40 and $0-100 \mathrm{~cm}$ soil profiles was 3.17 and $7.25 \mathrm{dS} / \mathrm{m}$ (2012.10), respectively, which was 88.81 and $73.27 \%$ lower than the corresponding initial $\mathrm{EC}_{\mathrm{e}}$ values.

There were still some salts leaching in the spring of 2013 before the start of irrigation (Fig. 4, 2013.3) after winter. The average $\mathrm{EC}_{\mathrm{e}}$ 

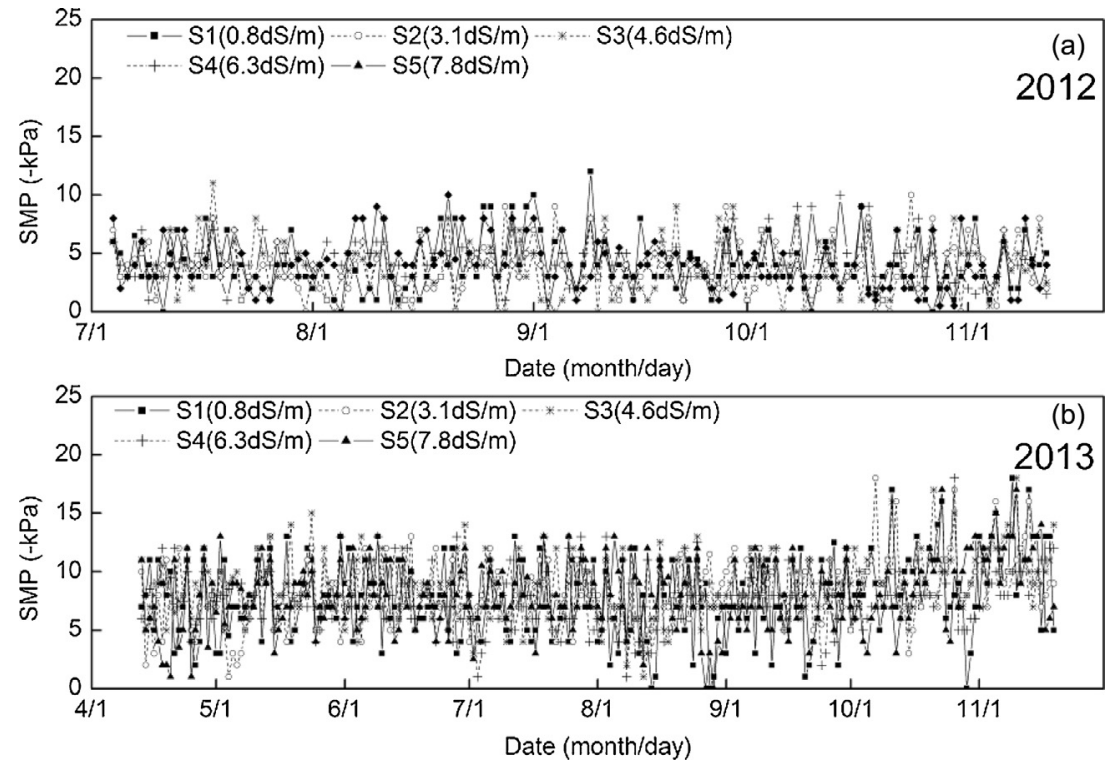

Fig. 2. The change in soil matric potential values of 8:00 at a depth of $20 \mathrm{~cm}$ immediately under emitters for different treatments in 2012 and 2013 .

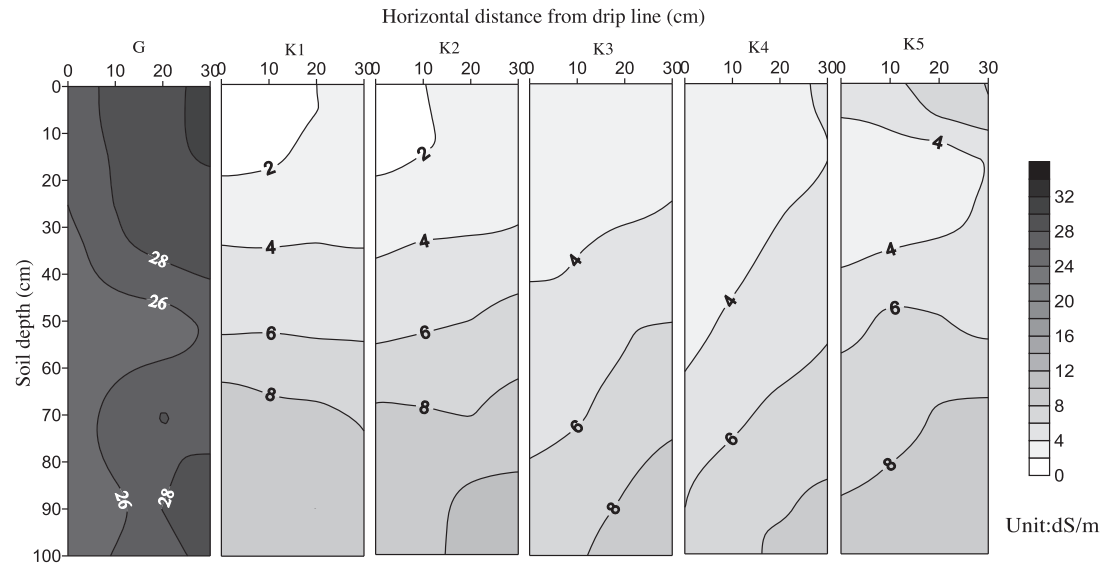

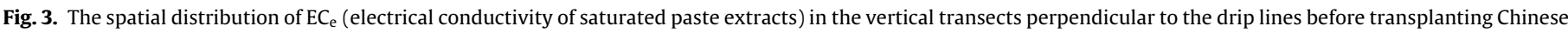
rose and in March 2014. G represents initial soil before transplanting Chinese rose; K1-K5 represents the five salinity treatments in irrigation water, respectively.

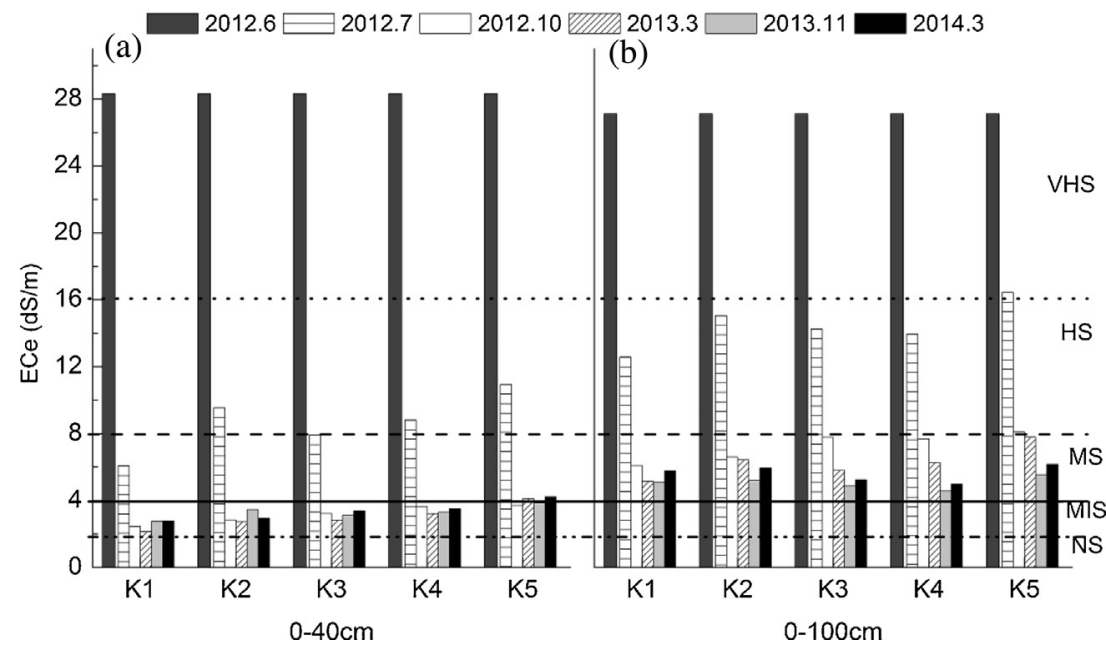

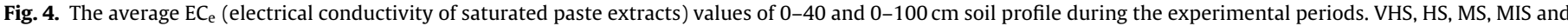

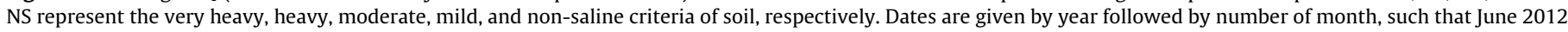
is 2012.6. 
values in $0-40 \mathrm{~cm}$ soil profile had been reduced to $<4 \mathrm{dS} / \mathrm{m}$ for K1-K4. However, salt accumulation occurred in the spring of 2014 (Fig. 4, 2014.3). The average $\mathrm{EC}_{\mathrm{e}}$ values in $0-40 \mathrm{~cm}$ soil profiles were $2.77,2.93,3.38,3.49$ and $4.22 \mathrm{dS} / \mathrm{m}$ for $\mathrm{K} 1-\mathrm{K} 5$, respectively (Fig. 4a, 2014.3). The average $\mathrm{EC}_{\mathrm{e}}$ values were 5.77, 5.95, 5.24, 4.98 and $6.17 \mathrm{dS} / \mathrm{m}$ for $\mathrm{K} 1-\mathrm{K} 5$ (Fig. 4b, 2014.3) in $0-100 \mathrm{~cm}$ soil profiles, respectively. Salt accumulation in the spring of 2014 indicated insufficient salt leaching from the upper soil layer in the winter of 2013. This may be due to the very low precipitation before 2014 and the controlled SMP of $-15 \mathrm{kPa}$ after 1 October 2013. This suggested that more winter irrigation amount should be applied for a year with less rainfall, and SMP above $-10 \mathrm{kPa}$ should be maintained after one year of planting. The lack of winter protection in 2013 may be another reason for the salt accumulation. Winter protection not only helps the plants resist cold, but also reduces soil surface evaporation, which may have an important role in reducing the buildup of salinity in soil layers (Li et al., 2015). In March 2014, the average $\mathrm{EC}_{\mathrm{e}}$ value for $\mathrm{K} 1-\mathrm{K} 5$ decreased to $<6 \mathrm{dS} / \mathrm{m}$ after reclamation in $0-40 \mathrm{~cm}$ soil profiles (Fig. $4 \mathrm{a}$ ), and the very highly saline soil became mildly saline for K1-K4, making it suitable for growth of plants that were moderately sensitive to salinity $(3-6 \mathrm{dS} / \mathrm{m})$.

In all, from June 2012 to March 2014, after the stages of enhanced salt leaching and normal water-salt regulation, the average $\mathrm{EC}_{\mathrm{e}}$ values were reduced by $90.23,89.65,88.08,87.67$ and $85.12 \%$, respectively, for $\mathrm{K} 1-\mathrm{K} 5$ compared with initial soil $\mathrm{EC}_{\mathrm{e}}$ values $(28.33 \mathrm{dS} / \mathrm{m})$ in $0-40 \mathrm{~cm}$ soil profiles; and correspondingly 78.74 , $78.07,80.67,81.64$ and $77.28 \%$ compared with the $27.13 \mathrm{dS} / \mathrm{m}$ in $0-100 \mathrm{~cm}$. The above results further demonstrated the effectiveness of drip-irrigation in salt leaching and its good prospects for saline water utilization (Malash et al., 2008; Meiri et al., 1992). Other studies also found that drip-irrigation was very applicable for utilization and reclamation of saline soils (Kang et al., 2010; Liu et al., 2012; Sun et al., 2013; Wan et al., 2012). In addition, significant differences only occurred in shallow soil layers among treatments when irrigated with saline water. This is likely related to the irrigation method and management used in the present study.

The soil salinity decreased with time and eventually resulted in a suitable soil environment for plants, when a suitable value of SMP was maintained at $0.2 \mathrm{~m}$ directly underneath drip-irrigation emitters in different growth years, using saline water of $<7.8 \mathrm{dS} / \mathrm{m}$.

\subsection{Growth and dry mass of Chinese rose}

The plant height and stem diameter of Chinese rose for different treatments during the experiment are shown in Fig. 5. Plant growth and dry weight decreased with increasing salinity in irrigation water, as also confirmed in crops and other plants (Chauhan et al., 2008; Karlberg et al., 2007; Malash et al., 2008; Mantell et al., 1985; Sonneveld et al., 1999; Valdez-Aguilar et al., 2011). Under our experimental conditions, there was greater plant height and stem diameter over the two years in $\mathrm{K} 1$ treatment using $0.8 \mathrm{dS} / \mathrm{m}$ irrigation water, and plants irrigated with $7.8 \mathrm{dS} / \mathrm{m}$ saline water had the poorest growth. Plant height and stem diameter decreased as irrigation water salinity increased, especially in 2013. This was most likely related to the lower rainfall (data not shown) and a lower controlled SMP. Similar results were also found in rose planted in saline silt-soil (Li et al., 2015) and wheat (Grewal, 2010). The result implied that water stress had a depressing effect on growth when also subject to different subsoil salinities.

The emergence rate and survival rate of Chinese rose for treatments $\mathrm{K} 1-\mathrm{K} 5$ are shown in Table 3. The average survival rate of rose was $94.40 \%$ in the first year, with no significant differences among the five treatments. There was a significant decrease in survival rates of K1-K5 in the emergence stage of plants in 2013 compared with initial survival rate in 2012, with the emergence rates reduced by $0.61,8.07,9.55,32.69$ and $46.79 \%$, respectively.
After that, the emergence rate or survival rate showed a slight decreasing trend and some roses died. This suggested that rose was more sensitive to salt at emergence stages of growth in the early planting period. Similar results were obtained by Rhoades et al. (1992) and Li et al. (2015), who reported that plants were more sensitive during emergence and early stages of seedling growth. Thus it is imperative to keep salinity in the root-zone low at these stages, and pre-emergence irrigation with non-saline water would play an important role in reducing the salt level in such cases (Chauhan et al., 2008; Li et al., 2015). Although buildup of salinity in the $0-40 \mathrm{~cm}$ soil layer occurred in the spring of 2014 , fewer roses of K1-K5 died in the emergence stage of 2014 compared with the significant decrease in emergence in 2013, likely due to the increasing tolerance of rose to salt as the plants grew larger and stronger.

At the end of 2013, some plants were collected and cut into roots and shoots to determine the dry mass (Table 4). Both root and shoot dry mass decreased with increasing salinity of water, with significant differences among the five treatments. This was likely due to the decreased plant growth and changes in physiology caused by irrigation with saline water. The water uptake, stomatal density, transpiration, net $\mathrm{CO}_{2}$ assimilation and leaf photosynthesis can be reduced as salinity of irrigation water increases (Bazihizina et al., 2012; Cabrera and Perdomo, 2003; Mantell et al., 1985; Rhoades et al., 1992; Rogers, 2001; Romero-Aranda et al., 2001; Suyama et al., 2007; Valdez-Aguilar et al., 2011). Dry matter production also declined (data not shown) due to the decreased light interception caused by the reduction of leaf area (Alarcon et al., 1994; Kutuk et al., 2004; Li and Stanghellini, 2001).

Root:shoot ratio increased with increasing salinity of irrigation water. Plants seemed to devote more dry matter to roots but less to shoots with increasing salinity of irrigation water. This is consistent with the results for rose planted in saline silt-soil under similar conditions of irrigation with saline water (Li et al., 2015). However, Valdez-Aguilar et al. (2011) reported that both root and shoot were equally affected with increasing $\mathrm{EC}_{\mathrm{iw}}$ as suggested by the lack of a significant effect on the shoot:root ratio of five species studied, and they thought that the growing season had a marked effect on the shoot:root ratio for some species. This could be associated with the different experimental environments and plant species, with five arbor landscape plants growing in a greenhouse in their study and bush-sized plants in the field in the present study.

\subsection{Salt tolerance threshold of Chinese rose}

Numerous field and laboratory experiments have been carried out to determine the salt tolerance of various crops and plants, and a number of models proposed and developed for plant salt tolerance response functions (Steppuhn et al., 2005). In the present study, two models were applied to determine the salinity response of rose. Model 1 was used to evaluate the effect of soil root-zone salt on relative emergence rate (RER) and relative dry weight (RDW) because its coefficients of determination (RER $\sim \mathrm{EC}_{\mathrm{e}}, R^{2}=0.8297$; $\mathrm{RDW} \sim \mathrm{EC}_{\mathrm{e}}, R^{2}=0.8485$ ) (Fig. 6) were higher than those of model 2 (RER $\sim \mathrm{EC}_{\mathrm{e}}, R^{2}=0.8164 ; \mathrm{RDW} \sim \mathrm{EC} \mathrm{e}, R^{2}=0.7835$ ). The salt tolerance threshold value of rose at emergence stages in the root zone of saline sandy loam soil was $2.39 \mathrm{dS} / \mathrm{m}$ according to the linear relationship between soil root-zone $\mathrm{EC}_{\mathrm{e}}$ at emergence stage; and emergence rate decreased by $27.39 \%$ for each unit of $\mathrm{EC}_{\mathrm{e}}$ increase in the root zone. The linear relationship between dry weight and average $\mathrm{EC}_{\mathrm{e}}$ in soil root-zone the over two years showed that the salt tolerance threshold value of rose during the growth period was $2.78 \mathrm{dS} / \mathrm{m}$, and dry weight decreased by $41.19 \%$ for each unit of $\mathrm{EC}_{\mathrm{e}}$ increase in the root zone. The value was similar to threshold values for rose, reported as $1-2.4$ and $1-3 \mathrm{dS} / \mathrm{m}$ in soilless and soil cultures, respectively, and determined by flower characteristics (De 

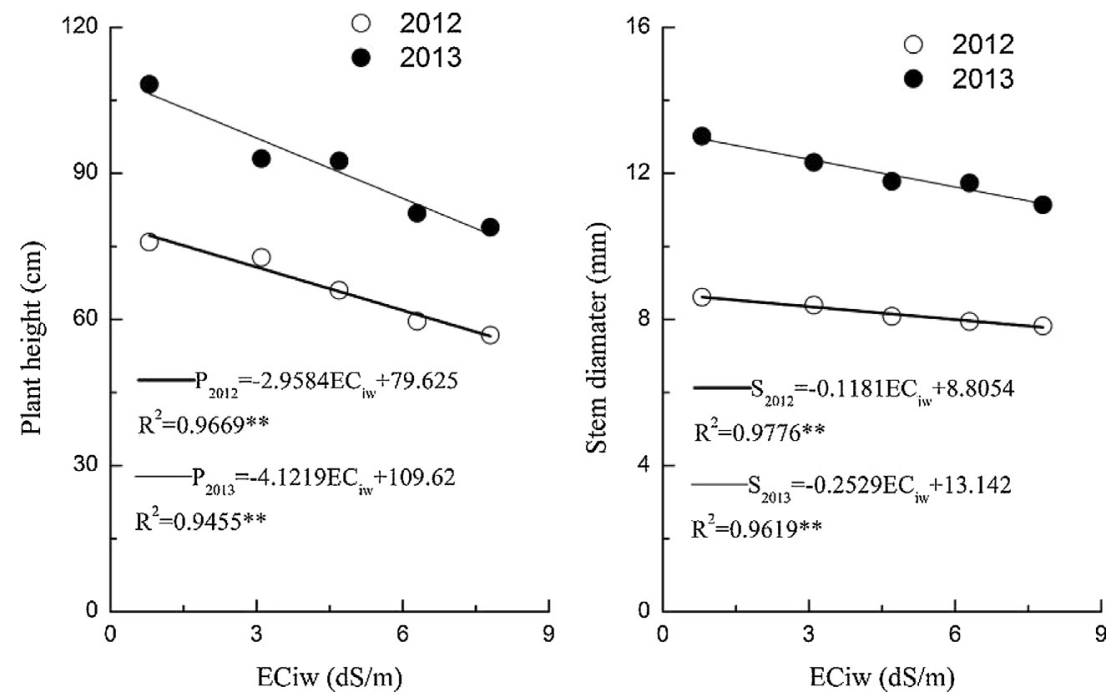

Fig. 5. The response of plant height and stem diameter of the two years to $\mathrm{EC}_{\mathrm{iw}}{ }^{*} p<0.05$.

Table 3

Chinese rose emergence and survival rate for different irrigation water quality ( $\left.\mathrm{EC}_{\mathrm{iw}}\right)$ from 2012 to 2014.

\begin{tabular}{|c|c|c|c|c|c|c|}
\hline \multirow[t]{2}{*}{ Treatments } & \multicolumn{3}{|c|}{ Emergence rate (\%) } & \multicolumn{3}{|c|}{ Survival rate (\%) } \\
\hline & 2012 & 2013 & 2014 & 2012 & 2013 & 2014 \\
\hline $\mathrm{K} 1(0.8 \mathrm{dS} / \mathrm{m})$ & - & $96.43 a$ & $96.36 a$ & $97.02 a$ & $96.43 a$ & $96.36 a$ \\
\hline $\mathrm{K} 2(3.1 \mathrm{dS} / \mathrm{m})$ & - & $88.10 \mathrm{a}$ & 86.06a & $95.83 a$ & 86.90a & 80.61ab \\
\hline $\mathrm{K} 3(4.7 \mathrm{dS} / \mathrm{m})$ & - & $84.52 \mathrm{a}$ & 83.81a & $93.45 a$ & 83.93a & 77.80ab \\
\hline $\mathrm{K} 4(6.3 \mathrm{dS} / \mathrm{m})$ & - & $62.50 \mathrm{ab}$ & $61.31 \mathrm{ab}$ & $92.86 a$ & 61.35ab & $51.68 b$ \\
\hline $\mathrm{K} 5(7.8 \mathrm{dS} / \mathrm{m})$ & - & $49.40 \mathrm{~b}$ & $47.41 \mathrm{~b}$ & $92.86 a$ & $47.62 b$ & $36.54 b$ \\
\hline
\end{tabular}

-, data of emergence rate not measured in 2012; values followed by different letters within the same year in column differ significantly at $p<0.05$.

Table 4

Chinese rose dry mass characteristic for different irrigation water quality $\left(\mathrm{EC}_{\mathrm{iw}}\right)$ until 2013.

\begin{tabular}{|c|c|c|c|c|}
\hline Periods & Treatments & Root dry mass ( $\mathrm{g}$ ) & Shoot dry mass ( $\mathrm{g}$ ) & Root:shoot ratio \\
\hline \multirow[t]{5}{*}{ 2012-2013 } & $\mathrm{K} 1(0.8 \mathrm{dS} / \mathrm{m})$ & $39.12 \mathrm{a}$ & $251.53 a$ & $0.1555 a$ \\
\hline & $\mathrm{K} 2(3.1 \mathrm{dS} / \mathrm{m})$ & $33.02 b$ & 197.51b & $0.1672 \mathrm{a}$ \\
\hline & $\mathrm{K} 3(4.7 \mathrm{dS} / \mathrm{m})$ & $26.35 c$ & $131.62 b c$ & $0.2002 \mathrm{ab}$ \\
\hline & $\mathrm{K} 4(6.3 \mathrm{dS} / \mathrm{m})$ & $22.14 \mathrm{c}$ & $105.59 c$ & $0.2097 b$ \\
\hline & $\mathrm{K} 5(7.8 \mathrm{dS} / \mathrm{m})$ & $12.11 d$ & $52.20 d$ & $0.2320 \mathrm{~b}$ \\
\hline
\end{tabular}

Values followed by different letters in column differ significantly at $p<0.05$.

Kreij and Berg, 1990; Feigin et al., 1989; Hughes and Hanan, 1978; Ishida et al., 1979; Sonneveld et al., 1999; Yaron et al., 1969; Zeroni and Gale, 1989). Using the U.S. Salinity Laboratory classification system of salinity tolerance in ornamental species, rose planted

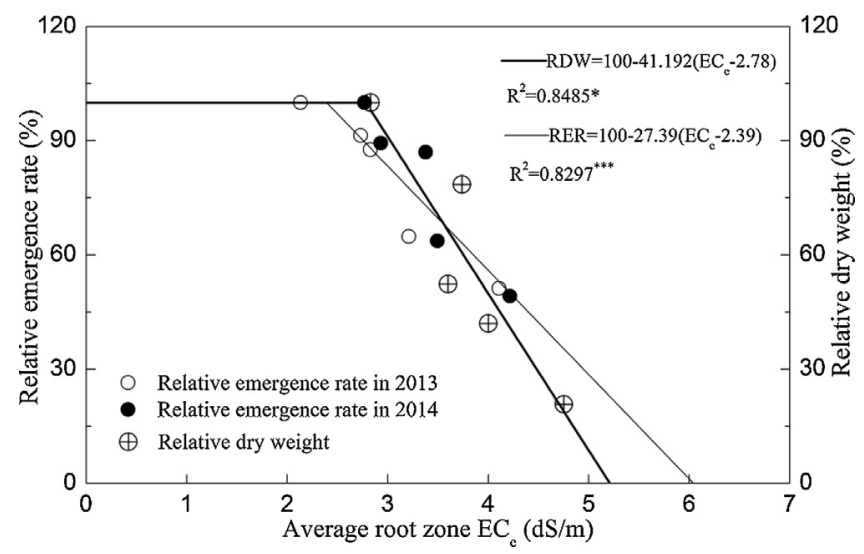

Fig. 6. The response of relative emergence rate of 2013 and 2014 and relative dry weight to average $\mathrm{EC}_{\mathrm{e}}$ in the root zone based on regression analysis (extrapolation model 1). ${ }^{* * *} p<0.001 ;{ }^{*} p<0.05$. in coastal saline sandy loam soil ranks as sensitive $(0-3 \mathrm{dS} / \mathrm{m})$ to salt at emergence stage and during the growth season, based on $\mathrm{EC}_{\mathrm{e}}$ (Miyamoto, 2008). Although the salt tolerance threshold in the emergence stage was slightly lower than in growth period, the dry mass production was more sensitive to salt than emergence rate as shown by the greater slope of the salt tolerance response function.

The effects of salinity of irrigation water on survival rate and dry weight were also analyzed using model 2 (Fig. 7). The STI of rose according to survival rate and dry weight were 8.32 and $6.03 \mathrm{dS} / \mathrm{m}$, respectively. Introducing the STI values based on survival rate and dry weight into model 2, respectively, showed that these characteristics were reduced by 60.69 and $61.13 \%$, compared with the corresponding values for non-saline water irrigation. The result indicated a slightly greater effect of saline irrigation on dry mass than on survival rate. The differences between the both values and $50 \%$ implied that other factors, such as rainfall or soil reclamation process, also affected the survival rate and dry mass of plant in addition to the salinity of irrigation water. It was also found that the maximum acceptable salinity for irrigation water suitable for rose growth under field conditions should not exceed $7.21 \mathrm{dS} / \mathrm{m}$ to maintain a survival rate of $>50 \%$. If taking the rose growth and landscape view (according to dry mass) into account, the maximum 


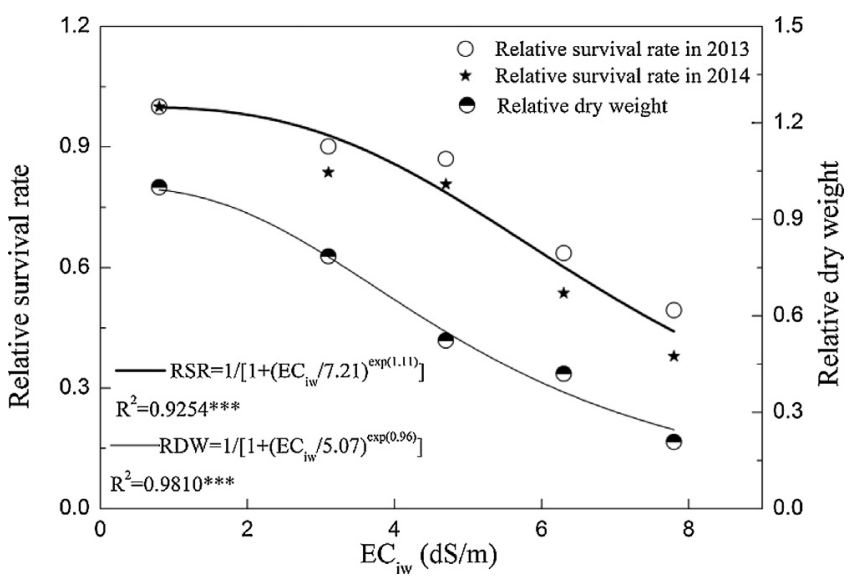

Fig. 7. The response of relative survival rate of 2013 and 2014 and relative dry weight to $\mathrm{EC}_{\mathrm{iw}}$ based on regression analysis (extrapolation model 2); ${ }^{* * *} p<0.001$.

acceptable salinity for irrigation water should not exceed $5.07 \mathrm{dS} / \mathrm{m}$ in order to obtain a dry mass of $>50 \%$.

\section{Conclusions}

Drip-irrigation with saline water was used for reclamation of very heavy coastal saline sandy loam soil and its effect on Chinese rose was evaluated. Regardless of salinity level of irrigation water, soil salinity decreased significantly with time. An increase in salinity of irrigation water had adverse effects on rose plant height, stem diameter and dry matter production. Rose devoted more dry matter to roots but less to shoots as suggested by the increasing root:shoot ratio. The soil salt in the root zone had significant effects on rose emergence rate during spring at seeding stage, implying that postgrowth and pre-emergence irrigation with fresh water played an important role in producing a higher survival rate before being supplemented with saline water at later growth stages. The salt tolerance threshold value of rose at the emergence stage in the soil root-zone was $2.39 \mathrm{dS} / \mathrm{m}$, and emergence rate decreased by $27.39 \%$ for each unit of $\mathrm{EC}_{\mathrm{e}}$ increase; while the corresponding value during the growth period was $2.78 \mathrm{dS} / \mathrm{m}$, and dry weight decreased by 41.19\% for each unit of $\mathrm{EC}_{\mathrm{e}}$ increase.

Overall, SMP above $-5 \mathrm{kPa}$ at $20 \mathrm{~cm}$ depth under the emitter in the first year and $-10 \mathrm{kPa}$ in the second year, and $6 \mathrm{~mm}$ of irrigation water, can be used as indicators for rose drip-irrigation scheduling using saline water at $<7.21 \mathrm{dS} / \mathrm{m}$ in initially saline sandy loam soils with a gravel-sand layer after tillage. Long-term field monitoring is needed to investigate the effectiveness of this method on plant growth. Moreover, other advantageous measures should also be introduced with this method, such as mulching with reeds, which are plentiful in coastal regions.

\section{Acknowledgements}

This study was supported by the National Key Technology R\&D Program of China (Grant nos. 2013BAC02B02, 2013BAC02B01 and 2011AA100507), the Knowledge Innovation Program of the Chinese Academy of Sciences (Grant No. KZCX2-YW-359), and the Action Plan for the Development of Western China of the Chinese Academy of Sciences (Grant No. KZCX2-XB3-16).

\section{References}

Akhter, J., Murray, R., Mahmood, K., Malik, K.A., Ahmed, S., 2004. Improvement of degraded physical properties of a saline-sodic soil by reclamation with kallar grass (Leptochloa fusca). Plant Soil 258, 207-216.
Alarcon, J.J., Sanchezblanco, M.J., Bolarin, M.C., Torrecillas, A., 1994. Growth, yield and water relations of normal fruited and cherry tomato cultivars irrigation with saline water. J. Hortic. Sci. 69, 283-288.

Bazihizina, N., Barrett-Lennard, E.G., Colmer, T.D., 2012. Plant growth and physiology under heterogeneous salinity. Plant Soil 354, 1-19.

Cabrera, R.I., Perdomo, P., 2003. Reassessing the salinity tolerance of greenhouse roses under soilless production conditions. Hortscience 38, 533-536.

Cai, X.Y., Niu, G.H., Starman, T., Hall, C., 2014. Response of six garden roses (Rosa hybrida L.) to salt stress. Sci. Hortic. 168, 27-32.

Chauhan, C.P.S., Singh, R.B., Gupta, S.K., 2008. Supplemental irrigation of wheat with saline water. Agric. Water Manage. 95, 253-258.

De Kreij, C., Berg, T.J.M.V.D., 1990. Nutrient uptake, production and quality of Rosa hybrida in rockwool as affected by electrical conductivity of the nutrient solution. Plant Nutr.: Physiol. Appl. 41, 519-523.

Dou, C.-Y., Kang, Y.-H., Wan, S.-Q., Hu, W., 2011. Soil salinity changes under cropping with Lycium barbarum L. and irrigation with saline-sodic water. Pedosphere 21, 539-548.

Feigin, A., Ganmore-Neumann, R., Gilead, S., 1989. Response of rose plants to $\mathrm{Cl}$ and $\mathrm{NO}_{3}$ salinity under different $\mathrm{CO}_{2}$ atmospheres. In: Proc. 7th Int. Congr. Soilless Culture, vol. 7, pp. 135-143.

Goldberg, D., Gornat, B., Rimon, D., 1976. Drip Irrigation - Principles, Design and Agricultural Practices. Drip Irrigation Scientific Publications, Israel.

Grewal, H.S., 2010. Response of wheat to subsoil salinity and temporary water stress at different stages of the reproductive phase. Plant Soil 330, 103-113.

Hughes, H.E., Hanan, J.J., 1978. Effect of salinity in water supplies on green-house rose production. J. Am. Soc. Hortic. Sci. 103, 694-699.

Ishida, A., Masui, M., Nukaya, A., Ogura, T., 1979. Salt tolerance of roses in sand and soil cultures. J. Jpn. Soc. Hortic. Sci. 47, 517-523.

Kang, Y., Chen, M., Wan, S., 2010. Effects of drip irrigation with saline water on waxy maize (Zea mays L. var. ceratina Kulesh) in North China Plain. Agric. Water Manage. 97, 1303-1309.

Kang, Y.H., 1998. Microirrigation for the development of sustainable agriculture. Trans. CASE 14 (Suppl.), 251-255.

Karlberg, L., Rockstrom, J., Annandale, J.G., Steyn, J.M., 2007. Low-cost drip irrigation: a suitable technology for southern Africa? An example with tomatoes using saline irrigation water. Agric. Water Manage. 89, 59-70.

Khoshgoftarmanesh, A.H., Shariatmadari, H., Vakil, R., 2003. Reclamation of saline soils by leaching and barley production. Commun. Soil Sci. Plant Anal. 34 2875-2883.

Kutuk, C., Cayci, G., Heng, L.K., 2004. Effects of increasing salinity and N-15-labelled urea levels on growth, N uptake, and water use efficiency of young tomato plants. Aust. J. Soil Res. 42, 345-351.

Li, X., Kang, Y., Wan, S., Chen, X., Chu, L., 2015. Reclamation of very heavy coasta saline soil using drip-irrigation with saline water on salt sensitive plants. Soil Tillage Res. http://dx.doi.org/10.1016/j.still.2014.10.005

Li, Y.L., Stanghellini, C., 2001. Analysis of the effect of EC and potential transpiration on vegetative growth of tomato. Sci. Hortic. 89, 9-21.

Liu, S., Kang, Y., Wan, S., Wang, Z., Liang, Z., Jiang, S., Wang, R., 2012. Germination and growth of Puccinellia tenuiflora in saline-sodic soil under drip irrigation. Agric. Water Manage. 109, 127-134.

Malash, N.M., Ali, F.A., Fatahalla, M.A., Khatab, E.A., Hatem, M.K., Tawfic, S., 2008 Response of tomato to irrigation with saline water applied by different irrigation methods and water management strategies. Int. J. Plant Prod. 2, 101-116.

Mantell, A., Frenkel, H., Meiri, A., 1985. Dirp irrigation of cotton with saline-sodic water. Irrig. Sci. 6, 95-106.

Mass, E.V., Hoffman, G.J., 1977. Crop Salt Tolerance - Current Assessment. U.S. Salinity Laboratory Agricultural Research Service.

Meiri, A., Frenkel, H., Mantell, A., 1992. Cotton response to water and salinity under sprinkler and drip irrigation. Agron. J. 84, 44-50.

Miyamoto, S., 2008. Salt Tolerance of Landscape Plants Common to the Southwest. Texas Water Resources Institute, pp. 1-37.

Oster, J.D., Shainberg, I., abrol, I.P., 1999. Reclamation of salt affected soils. In: Skaggs, R.W., Van Schilfgaarde, J. (Eds.), Agricultural Drainage. ASA-CSSA-SSSA, Madison, WI, pp. 659-691.

Prichard, T.L., Hoffman, G.J., Oster, J.D., 1985. Reclamation of saline organic soil. Irrig. Sci. 6, 211-220.

Qadir, M., Noble, A.D., Oster, J.D., Schubert, S., Ghafoor, A., 2005. Driving forces for sodium removal during phytoremediation of calcareous sodic and saline-sodic soils: a review. Soil Use Manage. 21, 173-180.

Rhoades, J.D., Bingham, F.T., Letey, J., Pinter, P.J., Lemert, R.D., Alves, W.J., Hoffman, G.J., Replogle, J.A., Swain, R.V., Pacheco, P.G., 1988. Reuse of drainage water for irrigation-results of imperial-valley study. 2. Soil-salinity and water-balance. Hilgardia 56, 17-44.

Rhoades, J.D., Kandiah, A., Mashali, A.M., 1992. The Use of Saline Waters for Crop Production Food and Agriculture Organization of the United Nations., pp. $1-132$.

Rogers, M.E., 2001. The effect of saline irrigation on lucerne production: shoot and root growth, ion relations and flowering incidence in six cultivars grown in northern Victoria, Australia. Irrig. Sci. 20, 55-64.

Romero-Aranda, R., Soria, T., Cuartero, J., 2001. Tomato plant-water uptake and plant-water relationships under saline growth conditions. Plant Sci. 160, 265-272.

Selassie, T.G., Jurinak, J.J., Dudley, L.M., 1992. Saline and sodic-saline soil reclamation: first order kinetic model. Soil Sci. 154, 1-7.

Sonneveld, C., Baas, R., Nijssen, H.M.C., de Hoog, J., 1999. Salt tolerance of flower crops grown in soilless culture. J. Plant Nutr. 22, 1033-1048. 
Steppuhn, H., van Genuchten, M.T., Grieve, C.M., 2005. Root-zone salinity. I. Selecting a product-yield index and response function for crop tolerance. Crop Sci. 45, 209-220.

Sumner, M.E., 1993. Sodic soils - new perspectives. Aust. J. Soil Res. 31, 683750.

Sun, J., Kang, Y., Wan, S., Hu, W., Jiang, S., Zhang, T., 2012. Soil salinity management with drip irrigation and its effects on soil hydraulic properties in north China coastal saline soils. Agric. Water Manage. 115, 10-19.

Sun, J.X., Kang, Y.H., Wan, S.Q., 2013. Effects of an imbedded gravel-sand layer on reclamation of coastal saline soils under drip irrigation and on plant growth. Agric. Water Manage. 123, 12-19.

Suyama, H., Benes, S.E., Robinson, P.H., Grattan, S.R., Grieve, C.M., Getachew, G., 2007. Forage yield and quality under irrigation with saline-sodic drainage water: greenhouse evaluation. Agric. Water Manage. 88, 159-172.
Valdez-Aguilar, L.A., Grieve, C.M., Razak-Mahar, A., McGiffen, M.E., Merhaut, D.J., 2011. Growth and ion distribution is affected by irrigation with saline water in selected landscape species grown in two consecutive growing seasons: spring-summer and fall-winter. Hortscience 46, 632-642.

Wan, S., Jiao, Y., Kang, Y., Hu, W., Jiang, S., Tan, J., Liu, W., 2012. Drip irrigation of waxy corn (Zea mays L. var. ceratina Kulesh) for production in highly saline conditions. Agric. Water Manage. 104, 210-220.

Wang, R., Kang, Y., Wan, S., Hu, W., Liu, S., Jiang, S., Liu, S., 2012. Influence of different amounts of irrigation water on salt leaching and cotton growth under drip irrigation in an arid and saline area. Agric. Water Manage. 110, 109-117.

Yaron, B., Zieslin, N., Halevy, A.H., 1969. Response of Baccara roses to saline irrigation. J. Am. Soc. Hortic. Sci. 94, 481-484.

Zeroni, M., Gale, J., 1989. Response of Sonia roses to salinity at three levels of ambient $\mathrm{CO}_{2}$. J. Hortic. Sci. 64, 503-511. 